\title{
Vijf jaar regionalisatie van de behandeling erectieprothese bij therapieresistente erectiele disfunctie in Nederland, de eerste uitkomsten en ervaringen
}

\author{
Eveline Broers · Jack Beck · Marij Dinkelman-Smit · Gert Dohle · Henk Elzevier · Kathleen D'Hauwers · \\ Wim Levens · Boaz Meijer · Garry Pigot - Brechje Ronkes · Janneke van Uhm - Jeannette Verkerk-Geelhoed • \\ Afina Glas
}

Geaccepteerd op: 11 januari 2022 / Published online: 16 februari 2022

(C) The Author(s) 2022

Samenvatting Sinds 2016 is de implantatie van een erectieprothese opgenomen in het basispakket voor patiënten die voldoen aan de indicatie en kwaliteitsvoorwaarden die zijn beschreven in het NVU-Standpunt. In dit artikel van de Nederlandse implanteurs zijn de data gebundeld van die eerste vijf jaar erectieprothese-implantatie. De patiënttevredenheid is met $82 \%$ groter dan vóór 2016 en $86 \%$ maakt daadwerkelijk gebruik van de erectieprothese. Deze getallen liggen hoger in de primaire groep dan in de re-implantatiegroep. Het risico op een ernstige complicatie is respectievelijk 5,8 en $7,5 \%$. Introductie van een ge-

drs. E. Broers $(\bowtie) \cdot d r$. W. Levens

afdeling Urologie, Máxima Medisch Centrum,

Veldhoven/Eindhoven, Nederland

eveline.broers@mmc.nl

dr. J. Beck · drs. J. Verkerk-Geelhoed

afdeling Urologie, St. Antonius Ziekenhuis, Nieuwegein, Nederland

dr. M. Dinkelman-Smit · dr. G. Dohle

afdeling Urologie, Erasmus MC, Rotterdam, Nederland

dr. H. Elzevier · drs. J. van Uhm

afdeling Urologie, LUMC, Leiden, Nederland

dr. K. D'Hauwers

afdeling Urologie, Radboud UMC, Nijmegen, Nederland

drs. B. Meijer

afdeling Urologie, UMCG, Groningen, Nederland

ACIBADEM International Medical Center, Amsterdam, Nederland

dr. G. Pigot · drs. B. Ronkes

afdeling Urologie, Amsterdam Universitair Medisch

Centrum, locatie VUmc, Amsterdam, Nederland

dr. A. Glas

afdeling Urologie, Zaans Medisch Centrum, Zaandam, Nederland valideerde PROM en intensievere samenwerking met seksuologen kunnen de patiënttevredenheid en het complicatierisico optimaliseren. Ook zal er een optimalisatie van volumes moeten komen.

Trefwoorden hydraulische erectieprothese · semirigide prothese $\cdot$ patiënttevredenheid

First result of patient outcome after five years of regionalisation in implanting penile prosthesis for therapy resistent erectile dysfunction in The Netherlands

Abstract Since 2016 the penile prosthesis is reimbursed when patients meet indication and quality criteria which are stated in the NVU statement. The Dutch implanters have bundled the data of their first five years of implanting penile prosthesis. Patient satisfaction is higher than previously with $82 \%$ and prosthesis use was reported in $86 \%$ of the patients. These numbers are higher in the primary group compared to the group with reimplantations. The risk of getting a serious complication is 5.8 and $7.5 \%$ respectively. Introducing validated PROMS and intensifying the collaboration with the seksuologists will optimize patient satisfaction and complication risk. Furthermore an optimalisation of national implantation volumes will be necessary.

Keywords inflatable penile prosthesis - malleable penile prosthesis $\cdot$ patient satisfaction

\section{Introductie}

De implantatie van een erectieprothese is in Nederland de laatste optie in de behandeling van erectiele disfunctie (ED). Als PDE 5-remmers, vacuümpomp, caverneuze injectietherapie en intra-urethrale behan- 
deling geen effect (meer) hebben, is een erectieprothese een optie. De erectieprothese wordt in de corpora cavernosa geïmplanteerd. Dat kan bestaan uit twee buigbare cilinders (semirigide prothese) of een IPP (inflatable penile prosthesis), een twee- dan wel driedelig hydraulisch systeem met twee oppompbare cilinders, een reservoir en een pompje. Bij een IPP wordt de penis erect door de cilinders op te pompen en na gebruik weer leeg te maken. De semirigide prothese wordt bij seks in de juiste positie gebogen, wat de penis een permanent semistijf uiterlijk geeft [1].

Plaatsing van een erectieprothese is een onomkeerbare behandeling. Na verwijdering van de prothese is er geen herstel meer mogelijk van de erectiele restfunctie. Ook wordt de penis bij gebruik van de prothese niet langer, waardoor de prothese voor patiënten niet altijd aan de verwachtingen voldoet. Tot slot is er een risico op infectie $(0,44-7 \%$ primair, $7-18 \%$ re-implantatie), suboptimale plaatsing of mechanisch falen $(6-43 \%)[2,3]$.

In het verleden werden erectieprotheses 5-10 keer per jaar geïmplanteerd in zeker 15 verschillende centra. De tevredenheid in een studie uit 1991 was slechts $40 \%$ en in een studie uit $200150 \%$ [4, 5]. Internationale studies tonen aan dat de uitkomsten van de behandeling beter zijn naarmate de uroloog vaker een erectieprothese implanteert [2, 6, 7]. Ook een strakkere indicatiestelling aan de hand van wetenschappelijk aangetoonde (relatieve) contra-indicaties en het toetsen van de verwachtingen van de patiënt door uroloog en seksuoloog zijn belangrijk in het optimaliseren van de uitkomsten [8, 9].

Op basis van onder andere deze argumenten zijn voorwaarden opgesteld waarop de verrichting 'implantatie erectieprothese' in september 2016 weer is opgenomen in het basispakket. Voor die tijd werd de behandeling jarenlang niet vergoed. Een belangrijke voorwaarde voor Zorginstituut Nederland was regionalisatie per urologische opleidingsregio. Dit leidde tot selectie van de zeven centra: het Zaans MC/Amsterdam UMC locatie VU (in VU alleen transgenders), Máxima MC, LUMC, Radboud UMC, St. Antonius Ziekenhuis, Erasmus MC en UMCG. Daarnaast is door de implanteurs zelf een standpunt geformuleerd. Hierin is opgenomen dat patiënt en seksuele partner behalve door de uroloog ook seksuologisch gecounseld worden omtrent de verwachtingen van implantatie en verandering van seksuologische activiteit. Ook zijn er indicaties en (relatieve) contraindicaties in opgenomen [10]. Sindsdien wordt er jaarlijks een bijeenkomst georganiseerd waar aandacht is voor complicaties van de behandeling, de opleiding tot implanteur, behaalde resultaten en proctorschap.

$\mathrm{Nu}$, vijf jaar na de regionalisatie van deze zorg, hebben we de eerste data samengevoegd en willen we in dit artikel de eerste uitkomsten en ervaringen laten zien. De belangrijkste vraag is of de patiënttevredenheid is toegenomen ten opzichte van de eerder vermelde scores van $40-50 \%[4,5]$. Ook zullen we de chirurgische uitkomsten vergelijken met die van de internationale (veelal hoogvolume)centra.

\section{Methode}

Vanaf 1 januari 2017 heeft elk centrum patiënt, ingreep, prothese en follow-up gestandaardiseerd bijgehouden in een database. Om voldoende followup te verkrijgen, hebben we de implantaties tot en met 31 december 2020 geïncludeerd. De getallen uit het UMCG van 2017 ontbreken. Vooraf is afgesproken dat variabelen bijgehouden gingen worden met betrekking tot patiëntkarakteristieken, oorzaak van de ED, merk en type prothese, primaire implantatie of re-implantatie (totale vervanging van een prothese welke voor 2017 werd geplaatst), operatieve variabelen, complicaties en, als allerbelangrijkste, de tevredenheid. Aangezien een gevalideerde patient reported outcome measure (PROM) ontbrak, werd de tevredenheid gemeten met ja/nee-vragen. Ook het gebruik van de prothese werd met een ja/nee-vraag gescoord.

Het is bekend dat een re-implantatie of revisie meer kans op complicaties geeft $[3,11,12]$ dan een primaire implantatie. We hebben daarom de resultaten onderverdeeld in primaire en re-implantaties. Het gaat hier om totale re-implantaties, niet enkel het vervangen van een pompje. De revisies binnen eenzelfde patiënt zijn ook gescoord, hieronder vallen bijvoorbeeld ook vervangingen bij een defecte prothese of vervanging van een semirigide prothese na acuut priapisme voor een IPP. Deze implantaties zijn niet opgenomen bij het totaal aantal implantaties, omdat we naar unieke patiënten hebben gekeken. Voor het overzicht van de complicaties hebben we per patiënt de ernstigste complicatie genomen. We keken naar milde voorbijgaande complicaties (scrotaal hematoom, pijnklachten, mictieklachten), laaggradige infecties die goed reageerden op tijdelijke antibiotica en niet leidden tot explantatie of revisie, malfunctie zonder reden tot revisie (bedieningsongemak), malfunctie leidend tot revisie en ernstige complicaties (zoals hooggradige infectie of erosie van de prothese) waarvoor explantatie of een salvageprocedure en re-implantatie nodig was.

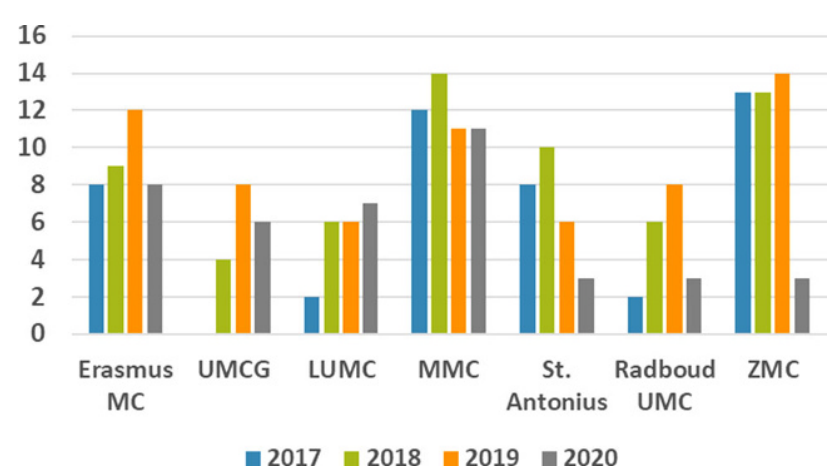

Figuur 1 Aantal erectieprotheses per jaar 


\section{Resultaten}

In totaal hebben 213 patiënten een erectieprothese gekregen verdeeld over de zeven landelijke centra. Dit betrof 173 primaire implantaties en 40 re-implantaties. Het totaal aantal implantaties per jaar was achtereenvolgens 45 in 2017, 62 in 2018, 65 in 2019 en 41 in 2020. Zie fig. 1. De gemiddelde leeftijd ten tijde van plaatsing van de prothese was 59 jaar (24-82 jaar) in de primaire groep en ook 59 jaar (24-81 jaar) in de reimplantatiegroep. De reden van de erectiele disfunctie was in de meeste gevallen postoperatief (vooral na radicale prostatectomie) en ten gevolge van diabetes mellitus (beide $n=55 ; 26 \%$ ) of het resultaat van vasculaire erectiele disfunctie ( $n=48 ; 22 \%)$. Er waren 18 patiënten $(8 \%)$ die een priapisme hadden gehad, waaronder zeven patiënten die volgens het nieuwe standpunt na langdurig priapisme (> 72 uur) semiacuut een erectieprothese kregen. Tot slot waren er negen patiënten ( $4 \%$ ) met een erectiele disfunctie bij een kromstand op basis van de m. peyronie. Zie tab. 1 .

\section{Tevredenheid}

In de primaire groep is $86 \%(135 / 157)$ tevreden. Redelijke tevreden zijn 1,9\%, en ontevreden $12 \%$. Van 16 patiënten ontbraken deze gegevens. In de re-implantatiegroep is $63 \%$ tevreden (24/38), 7,9\% redelijk tevreden en $29 \%$ ontevreden. Van twee patiënten ontbraken deze gegevens. Van de primair geïmplanteerde groep gebruikt $87 \%$ de prothese (140/161). Van 12 patiënten ontbraken de data. In de re-implantatiegroep gebruikt $80 \%$ de prothese (32/40).

\section{Complicaties en revisies}

In de primaire groep waren er complicaties geregistreerd bij in totaal $32 \%$ van de patiënten $(55 / 173)$. In de re-implantatiegroep was dit het geval bij $58 \%$ (23/40) van de patiënten. Er waren 45 revisie-ingrepen bij 23 unieke patiënten in de primaire groep en 15 revisie-ingrepen bij 11 unieke patiënten in de reimplantatiegroep. Ofwel, $13 \%$ van primair geïmplanteerde en $29 \%$ van de re-implantatiepatiënten moest een of meer revisies ondergaan. De meest voorkomende complicaties waren mild en voorbijgaand van aard, zoals een scrotaal hematoom, LUTS, pijn aan de glans penis of een doof gevoel in de penis. Milde complicaties kwamen in beide groepen even vaak voor. Een laaggradige infectie die afdoende kon worden behandeld met antibiotica, enige geaccepteerde malfunctie van de prothese, zoals een floppy glans, of een wat minder goed bedienbaar pompje, evenals malfunctie (of malpositie) waarvoor een vorm van revisie nodig was, kwamen vaker voor in de reimplantatiegroep. Zie tab. 2.

Een ernstige complicatie, zoals een hooggradige infectie of een erosie van prothese, waarbij in de meeste gevallen uiteindelijk de prothese geëxplan-
Tabel 1 Karakteristieken en uitkomsten

\begin{tabular}{|l|c|c|}
\hline & primaire prothese & re-implantatie \\
\hline leeftijd (jaar) & $59(24-82)$ & $59(24-81)$ \\
\hline OK-tijd (min) & $86(33-240)$ & $105(23-270)$ \\
\hline patiënten met DM & $42 \%$ & $40 \%$ \\
\hline prothese in situ & $95 \%$ & $98 \%$ \\
\hline gebruik & $87 \%$ & $80 \%$ \\
\hline tevredenheid 'ja' & $86 \%$ & $63 \%$ \\
\hline tevredenheid 'redelijk' & $1,9 \%$ & $7,9 \%$ \\
\hline tevredenheid 'nee' & $12 \%$ & $29 \%$ \\
\hline DM diabetes mellitus & & \\
\hline
\end{tabular}

Tabel 2 Complicaties

\begin{tabular}{l|c|c|}
\hline type complicatie & primair $n=173$ & re-implantatie $n=40$ \\
\hline mild en voorbijgaand & $14 \%(n=24)$ & $13 \%(n=5)$ \\
\hline laaggradige infectie waarvoor AB & $5,8 \%(n=10)$ & $10 \%(n=4)$ \\
\hline malfunctie expectatief & $1,7 \%(n=3)$ & $7,5 \%(n=3)$ \\
\hline malfunctie waarvoor revisie & $4,6 \%(n=8)$ & $20 \%(n=8)$ \\
\hline ernstige complicatie & $5,8 \%(n=10)$ & $7,5 \%(n=3)$ \\
\hline$A B$ antibiotica & &
\end{tabular}

teerd moest worden, kwam in de primaire groep voor bij 5,8\% $(n=10 / 173)$ en in de re-implantatiegroep bij $7,5 \%(n=3 / 40)$ van de patiënten. Hieronder valt ook één patiënt die een urethrastrictuur ontwikkelde waarvoor een urethraplastiek volgde en één patiënt bij wie een spoedlaparotomie geïndiceerd was na een darmperforatie die optrad door het verwijderen van een intra-abdominaal gelegen reservoir.

Ten tijde van het inleveren van de databases (juli 2021) had in de primaire groep $95 \%$ van de patiënten nog een prothese in situ en in de re-implantatiegroep was dat bij $98 \%$ van de patiënten het geval.

\section{Acuut priapisme}

Er zijn zeven patiënten met een acuut priapisme (>72 uur bestaand) geïmplanteerd binnen een periode van zes weken volgens het 'Standpunt erectieprothese' [10]. Bij alle patiënten is een semirigide prothese geïmplanteerd. Bij één patiënt trad een postoperatieve infectie op, waarna de prothese is vervangen door een nieuwe semirigide prothese na uitgebreid spoelen (salvageprocedure). Er is daarna geen complicatie meer geweest bij deze patiënt. Bij een van de patiënten is de semirigide prothese later vervangen door een IPP. Deze patiënt kreeg later een eenzijdige distale dislocatie (perforatie corpora met intacte huid); hierbij is een distale corporaplastiek gedaan en tot nu toe is de patiënt tevreden. Alle zeven patiënten hebben nog een prothese in situ. Vijf patiënten zijn tevreden en gebruiken de prothese, één patiënt is ontevreden en gebruikt de prothese niet en van één patiënt zijn deze gegevens onbekend. 


\section{Type en merk prothese}

In totaal zijn er 41 semirigide protheses (19\%) geplaatst en 171 IPP's (81\%). Van één patiënt is niet bekend welke prothese er is geïmplanteerd. Van alle erectieprotheses waren er 118 van de firma Boston Scientific (55\%) en 96 van de firma Coloplast (45\%). Van de patiënten met een IPP was $84 \%$ tevreden versus $70 \%$ van de patiënten met een semirigide prothese (primaire implantaties en re-implantaties). Redelijk tevreden waren respectievelijk 3,2 en $2,7 \%$. De prothese wordt door respectievelijk 88 versus $74 \%$ van de patiënten gebruikt.

De gemiddelde operatieduur was 59 minuten voor een primaire semirigide prothese en 93 minuten voor een primaire IPP. Voor de re-implantatie lag dit op 75 minuten voor een semirigide en 110 minuten voor een IPP. Bij $63 \%$ van de patiënten werd het reservoir retropubisch (Retzius) geplaatst, bij $17 \%$ in de subrectus, bij $2 \%$ ectoop (plaatsing via lieskanaal anterieur van de fascia transversalis) en bij $2 \%$ intra-abdominaal. In $16 \%$ van de gevallen werd de positie niet vastgelegd.

\section{Discussie}

Analyse van de resultaten van erectieprothese-implantatie na regionalisatie en een gestandaardiseerde indicatie en bij voldoen aan de kwaliteitsvoorwaarden laat zien dat de tevredenheid van patiënten na implantatie sterk verbeterd is ten opzichte van 2001. Een tevredenheid van $86 \%$ bij een primair geïmplanteerde erectieprothese komt overeen met de cijfers uit de internationale literatuur [3, 13, 14]. De cijfers voor de re-implantatiegroep liggen een stuk lager met $63 \%$. Er is dus nog verbetering mogelijk, maar ten opzichte van de oudere Nederlandse data is er een flinke stap gezet [5]. Tevredenheid is gescoord met een simpele ja/nee-vraag. De seksuele partners zijn niet bij beantwoording van deze vraag betrokken geweest en ook de timing van de vraag is niet gestandaardiseerd. Om de tevredenheid betrouwbaarder te kunnen scoren, willen we in de nabije toekomst een PROM introduceren en de tevredenheid van de partner meten. De tevredenheid van patiënt en partner hangt deels ook samen met goede indicatiestelling en verwachtingsmanagement. Hierin hebben de implanterend uroloog en de seksuoloog een even belangrijke taak. Ieder prothesecentrum heeft zijn eigen zorgketen georganiseerd waarin samenwerking is opgenomen met een of meerdere NVVS-seksuologen. Echter, niet elk centrum kan een vergoed consult met een seksuoloog aanbieden. Om de toegankelijkheid van de seksuologische zorg te verbeteren, zou het helpen als dit vanuit de zorgverzekering geregeld zou zijn.

Van de primair geïmplanteerde patiënten onderging $13 \%$ één of meerdere revisies. In een review van bijna 15.000 Amerikaanse primaire implantaten was de re-operatieratio 6,4\% [7]; in de re-implantatiegroep op $27,5 \%$. Dat het percentage revisies hoger ligt in de re-implantatie groep is bekend $[3,11,12]$. Het aantal ernstige complicaties ligt tussen de 5,8 en $7,5 \%$. In internationale series ligt dit getal lager; rond de 1-4\% $[15,16]$. De komende jaren willen we een verbeterslag maken in complicatie- en revisiepercentages door scholing, proctorschap en landelijke complicatiebesprekingen te continueren, de leercurve te doorlopen en door volumevergroting.

Nieuw in het standpunt is de indicatie 'plaatsen semirigide prothese bij een langdurig ischemisch priapisme' (>72 uur) binnen zes weken [10]. De reden hiervoor is dat bij te lang wachten er fibrosering van de corpora optreedt met op den duur verkorting van de penis [17-19]. Het snel plaatsen van een semirigide prothese spaart de penislengte en dit geeft een tevredener patiënt. Na enige maanden van rust kan de semirigide prothese vervangen worden door een IPP indien de patiënt dat wenst. Wij hebben zeven patiënten geregistreerd bij wie semiacuut een semirigide prothese is geïmplanteerd. Een van deze mannen heeft een vervanging gekregen van semirigide naar een IPP. De vraag is of er in Nederland niet meer acute priapisten zijn geweest die in aanmerking kwamen voor een prothese. Waarschijnlijk moeten de verwijsstromen beter op gang komen. Ook patiënten met een priapisme van $>36$ uur zouden wellicht al overlegd kunnen worden met een uroloog binnen een prothesecentrum, zodat in gezamenlijkheid aan de hand van patiëntkarakteristieken alvast een plan kan worden gemaakt zoals wordt aanbevolen in de recente richtlijn van de American Urological Association (AUA) [17].

In de meeste ziekenhuizen is in 2020 een daling van het aantal erectieprotheses te zien, welke toe te schrijven is aan de COVID-pandemie. Overigens wil het niet zeggen dat ziekenhuizen die geen daling laten zien, geen last hebben gehad van deze pandemie. Hun aantal protheses zou zonder COVID waarschijnlijk hoger zijn uitgevallen, aangezien in alle ziekenhuizen de wachtlijst is gegroeid. Wij zullen als Nederlandse implanteurs in de toekomst kritisch blijven kijken naar de aantallen per centrum (fig. 1).

Het aantal patiënten dat een erectieprothese krijgt, is in Nederland aan de lage kant. Vóór regionalisatie was de inschatting dat er per jaar 100-120 implantaties zouden plaatsvinden. In 2019 werden er landelijk de meeste protheses geïmplanteerd en dat waren er slechts 65. Er is naar onze mening nog een grote groep patiënten die deze behandeling nog niet aangeboden krijgt doordat er geen doorverwijzing plaatsvindt naar een prothesecentrum. Het is aan ons als implanteurs om de erectieprothese op de kaart te zetten, voorlichting te geven aan zowel patiënten als urologen en de zorgketens te optimaliseren. Het kan ook zijn dat door de strenge selectiecriteria in Nederland er mensen afvallen die wellicht in het buitenland wel geïmplanteerd worden. We hebben geen inzicht in de aantallen patiënten die om die reden niet in aanmerking komen voor een erectieprothese. 


\section{Conclusie}

Deze analyse laat zien dat de tevredenheid na het plaatsen van een erectieprothese na regionalisatie van de ingreep is toegenomen ten opzichte van eerdere Nederlandse studies. Dit komt zeer waarschijnlijk doordat de indicatiestelling door het standpunt goed is omschreven, de aantallen per implanteur hoger liggen en er betere preoperatieve begeleiding is van een seksuoloog. Ook gecoördineerde training en transparante bespreking van uitkomsten kunnen hieraan bijdragen. Er is echter ruimte voor verbetering van deze zorg met op de eerste plaats het verbeteren van de tevredenheid en op de tweede plaats het verbeteren van chirurgische uitkomsten. We hebben hiervoor een stappenplan gemaakt, waarbij ten eerste de uitkomstmaat wordt verbeterd met behulp van introductie van PROMS. Ten tweede is de seksuologische zorg nog niet voor iedere patiënt makkelijk toegankelijk, omdat deze zorg niet overal voor vergoeding in aanmerking komt. Daarnaast zullen we zelf moeten kijken naar de volumes per centra en zullen we verwijzers moeten blijven wijzen op het doorsturen van de mannen die lijden onder hun erectiele disfunctie, ondanks de gevolgde therapie. Dit laatste is van belang, omdat het aantal mannen dat in Nederland geïmplanteerd wordt laag is ten opzichte van de ons omringende landen en ten opzichte van Amerika.

Open Access This article is distributed under the terms of the Creative Commons Attribution 4.0 International License (http://creativecommons.org/licenses/by/4.0/), which permits unrestricted use, distribution, and reproduction in any medium, provided you give appropriate credit to the original author(s) and the source, provide a link to the Creative Commons license, and indicate if changes were made.

\section{Literatuur}

1. Ronkes B, Glas AS. The penile prosthesis for severe erectile dysfunction: re-introduction in the Netherlands. Tijdschr Urol. 2018;8(8):145-54.

2. Li K, Brandes ER, Chang SL, Leow JJ, et al. Trends in penile prosthesis implantation and analysis of predictive factors for removal. World J Urol. 2019;37(4):639-46.

3. Minervini A, Ralph DJ, Pryor JP. Outcome of penile prosthesis implantation for treating erectile dysfunction: experience with 504 procedures. BJU Int. 2006;97(1):129-33.

4. Meuleman EJH. Teleurstellende langetermijnervaringen van patiënten met een erectieprothese. Ned Tijdschr Geneeskd. 2001;145:787-90.

5. Tuyn EA, Meuleman EJH, Sabbe BGC, Bierkens PB. Ervaringen van patienten met de hydraulische erectieprothese. Ned Tijdschr Geneeskd. 1991;135:518-22.

6. Henry GD, Kansal NS, Callaway M, et al. Centers of excellence concept and penile prostheses: an outcome analysis. JUrol. 2009;181(3):1264-8.

7. Onyeji IC, Sui W, Pagano MJ, et al. Impact of surgeon case volume on reoperation rates after inflatable penile prosthesis surgery. J Urol. 2017;197(1):223-9.

8. Osmonov D, Christopher AN, Blecher GA, et al. Clinical recommendations from the European society for sexual medicine exploring partner expectations, satisfaction in male and phalloplasty cohorts, the impact of penile length, girth and implant type, reservoir placement, and the influence of comorbidity. J Sex Med. 2020;17(2):210-37.

9. Huynh LM, Osman MM, Yafi FA. Risk profiling in patients undergoing penile prosthesis implantation. Asian J Androl. 2020;22(1):8-14.

10. Glas A, Kropman R, Beck J, et al. NVU-Standpunt. Indicatie en kwaliteitsvoorwaarden erectieprothese. Utrecht: NVU; 2016.

11. Caire AA, Boonjindasup A, Hellstrom WJG. Does a replacement or revision of an inflatable penile prosthesis lead to decreased patient satisfaction. Int J Impot Res. 2011;23(2):39-42.

12. Wintner A, Lentz AC. Inflatable penile prosthesis: considerations in revision surgery. Curr Urol Rep. 2019;20(4):1-7.

13. Akakpo W, Pineda MA, Burnett AL. Critical analysis of satisfaction assessment after penile prosthesis surgery. Sex MedRev. 2017;5(2):244-51.

14. Jorissen C, De Bruyna H, Baten E, Renterghem K van. Clinical outcome: patient and partner satisfaction after penile implant surgery. Curr Urol. 2019;13(2):94-100.

15. Scherzer ND, Dick B, Gabrielson AT, et al. Penile prosthesis complications: planning, prevention, and decision making. SexMed Rev. 2019;7(2):349-59.

16. Narang GL, Figler BD, Coward RM. Preoperative counseling and expectation management for inflatable penile prosthesis implantation. Transl Androl Urol. 2017;6(S5):S869-S80.

17. Bivalacqua TJ, Allen BK, et al. Acute ischemic priapism: an AUA/SMSNA guideline. J Urol. 2021;206(5):1114-21. https://doi.org/10.1097/JU.0000000000002236.

18. Sedigh O, Rolle L, Negro CLA, et al. Early insertion of inflatable prosthesis for intractable ischemic priapism: our experience and review of the literature. Int J Impot Res. 2011;23(4):158-64.

19. Capece M, La Rocca R, Mirone V, et al. A systematic review on ischemic priapism and immediate implantation: do we need more data? Sex Med Rev. 2019;7(3):530-4.

\section{drs. Eveline Broers, uroloog}

dr. Jack Beck, uroloog

dr. Marij Dinkelman-Smit, uroloog

dr. Gert Dohle, uroloog

dr. Henk Elzevier, uroloog

dr. Kathleen D'Hauwers, uroloog

dr. Wim Levens, uroloog

drs. Boaz Meijer, uroloog

dr. Garry Pigot, uroloog

drs. Brechje Ronkes, uroloog

drs. Janneke van Uhm, uroloog

drs. Jeannette Verkerk-Geelhoed, verpleegkundig specialist urologie

dr. Afina Glas, uroloog 